\title{
Interdependência entre os níveis de atenção do Sistema Único de Saúde (SUS): significado de integralidade apresentado por trabalhadores da Atenção Primária
}

Lilian Magda de Macedo(a)

Sueli Terezinha Ferrero Martin ${ }^{(b)}$

Macedo LM, Martin STF. Interdependence between the levels of care in Brazilian Health Sistem (SUS): meanings of integrality reported by primary care workers. Interface (Botucatu). 2014; 18(51):647-59.

Integrality constitutes an important principle of the SUS, achieved through the struggles of the Brazilian health movement. It represents an expansion of the concepts of health and illness, to include the social determinants of healthcare needs. Intending to investigate the meanings of integrality reported by primary care workers, a study was developed in a medium-sized municipality in the state of São Paulo, concerning distinct technological work organization models in primary healthcare units. Among the results, the dimension of system integrality appeared with greatest frequency, according to analysis on focus groups. The workers pointed out difficulties in integration and communication between the healthcare levels, determined by selective social policies and medium/high-technology services delegated to the private market. The theoretical-philosophical framework of this study was based on cultural-historical psychology, taking into consideration the categories of work/activity, consciousness, mediation and totality.

Keywords: Integrality. Primary health care. Cultural-historical psychology. Social policies. Work.
A Integralidade constitui um importante princípio do SUS, conquistado com as lutas do movimento sanitário brasileiro. Representa ampliação dos conceitos saúde e doença, abarcando os determinantes sociais das necessidades em saúde. Pesquisa com o objetivo de investigar os significados de Integralidade apresentados por trabalhadores da Atenção Primária foi desenvolvida em munícipio de médio porte paulista, envolvendo distintos modelos tecnológicos de organização do trabalho nas Unidades Básicas de Saúde. Dentre os resultados, a dimensão de Integralidade do Sistema apresentou-se com maior frequência, conforme análise a partir de grupos focais. Os trabalhadores apontaram dificuldades de integração e comunicação entre os níveis de atenção à saúde, determinadas por políticas sociais seletivas e serviços de média/alta tecnologia delegados ao mercado privado. Os aportes teórico-filosóficos do estudo pautaram-se na Psicologia Histórico-Cultural, a partir das categorias: trabalho/atividade; consciência; mediação e totalidade.

Palavras-chave: Integralidade. Atenção Primária em Saúde. Psicologia históricocultural. Políticas sociais. Trabalho. (a) Psicóloga. Rua Antônio Sabino Santa Rosa, 70, bloco D, apto 44. Botucatu, SP, Brasil. 18606-140.

limagda@hotmail.com (b) Unesp - Univ Estadual Paulista, Faculdade de Medicina de Botucatu,

Departamento de Neurologia, Psicologia e Psiquiatria. Botucatu, SP, Brasil. 


\section{Integralidade e Atenção Primária à Saúde}

A concepção de Integralidade esteve presente desde as lutas do movimento da Reforma Sanitária Brasileira (RSB). Traz as prerrogativas de se compreender saúde e doença como processo determinado pelas condições sociais e de classe de indivíduos e populações.

As décadas de 1970/1980 representaram contexto de industrialização e redemocratização no Brasil. Movimentos sociais apontavam as contradições dos investimentos públicos destinados aos complexos hospitalares: acesso à saúde como "bem de consumo".

Diante da hegemonia do saber biologicista e patológico a orientar as políticas de saúde, as lutas pela reestruturação dos serviços pautavam-se pela universalização do acesso e equidade na oferta, além de se guiarem pela ampliação do conceito de necessidades em saúde.

Os conhecimentos produzidos pelas Ciências Sociais e Humanas embasaram críticas ao reducionismo da Medicina e Biologia, sinalizando para a multideterminação dos objetos que compõem o campo: carências sociais e históricas, em interface econômicas, inter-relacionais, culturais e subjetivas ${ }^{1}$.

Cecílio ${ }^{2}$ organiza as necessidades em saúde em grupos: aqueles relativos às condições de vida (posição social que as pessoas ocupam na sociedade/acesso à infraestrutura básica); relativos ao acesso a serviços/tecnologias; os que dizem respeito às relações sociais e vínculos entre usuário-equipe, garantindo seguimento do cuidado; relativos à autonomia dos usuários no modo de viver.

O princípio doutrinário da Integralidade, assentado na Constituição Federal de 1988, é articulador dos níveis de complexidade do Sistema Único de Saúde (SUS): aglutinando ações assistenciais e preventivas em quaisquer dos âmbitos de prestação de cuidado, do primário ao terciário.

Ao considerarmos a história do movimento sanitário e a história da organização dos serviços públicos no Brasil, compreendemos a Integralidade enquanto um conceito síntese do processo saúdedoença. A organização do trabalho nas instituições, de outro ângulo, nos apresenta a complexidade para sua efetivação.

De fato, nos anos setenta, o antigo sistema de saúde se estruturou de modo polar: de um lado, o Instituto Nacional de Assistência Médica da Previdência Social (INAMPS) se ocupou das ações assistenciais, organizando os serviços para responder à demanda espontânea; de outro, o Ministério da Saúde, naquele arranjo, deveria se ocupar daquelas outras necessidades de saúde pública. Indiscutivelmente, tal arranjo não favorece a melhoria da saúde da população. A criação do SUS modificou esse arranjo institucional, mas não necessariamente transformou as práticas dos serviços, de modo a articular a prevenção e a assistência, como diz o texto constitucional. ${ }^{3}$ (p. 1413)

A Integralidade, no cotidiano dos serviços, constitui a capacidade dos profissionais em responder ao sofrimento/adoecimento demandado pelos usuários, assim como, de modo articulado, identificar e ofertar, para cada situação singular, ações/procedimentos preventivos ${ }^{3}$.

Por outro lado, na organização e modus operandi da prática em saúde, relacionam-se revisão e reestruturação contínua do processo de trabalho, com vistas às diferentes necessidades individuais 3 3.4 $^{\text {. }}$

Para tanto, faz-se primordial não conceber os usuários somente como depositários de doenças ou como objeto de ações das unidades. A concepção dos indivíduos atendidos contemplando a totalidade de suas necessidades e potencialidades exige, para sua efetivação, a horizontalização dos programas fornecidos, articulando as demandas espontâneas da população àquelas programadas pelas unidades ${ }^{3,4}$.

A partir dessa conceituação, a Atenção Primária constitui um lócus privilegiado para a efetivação da Integralidade, tendo em vista suas ações fundamentadas na proximidade e conhecimento do território adscrito, no acolhimento e no acompanhamento longitudinal aos usuários.

O processo de trabalho das Unidades Básicas de Saúde (independentemente de seu modelo técnico e assistencial) implica o planejamento e execução de ações a partir de um olhar atento para 
os determinantes sociais do processo saúde-doença, pautando-se na revisão contínua de seu próprio fazer, em busca da promoção da máxima autonomia dos indivíduos.

Para Schraiber e Mendes-Gonçalves' ${ }^{1}$, a Integralidade deve partir dos conhecimentos sobre a vida cotidiana: os saberes tecnológicos (científicos e não científicos) relativos ao adoecimento e a recuperação, possibilitando que os trabalhadores possam ter ampliadas suas concepções do que sejam as necessidades expressas por indivíduos e populações atendidas.

A concepção ampliada do processo saúde-doença consistiria numa dimensão da "práxis emancipatória" decorrente das intervenções das unidades, visando a promoção de autonomia.

Nesse sentido, os serviços de saúde precisam criar espaços para a emergência de novas necessidades (aquelas silenciosas, não identificadas pelos próprios usuários), resgatando e valorizando os conhecimentos da vida cotidiana relativos a saúde e doença ${ }^{1}$.

Pesquisas desenvolvidas por Starfield ${ }^{5}$ comprovaram que nações com sistemas de saúde centrados na Atenção Primária à Saúde (APS) obtêm melhores resultados em indicadores sociais, com maior racionalidade. Assim, enfrentam diretamente os agravos decorrentes das grandes iniquidades no acesso a bens e serviços. Nesse processo, igualmente produzem e reproduzem valores sociais.

A Atenção Primária adquire ainda função de coordenação das Redes Atenção à Saúde (RAS), objetivando a efetivação da atenção integral a partir da gestão de serviços organizados em Redes, conforme a Portaria $2488 / 11^{6}$.

O modus operandi do cuidado primário no Brasil constituiu-se, ao longo da história do SUS, de diversos modelos assistenciais, com a exigência de articulação entre níveis de atenção: a denominada centralidade do cuidado realizado em Rede ${ }^{7-9}$.

Desde 1994, a Política Nacional de Atenção Básica estrutura-se guiada pela Estratégia Saúde da Família (ESF), somada ao Programa Agente Comunitário de Saúde (PACS), com o objetivo de potencializar os princípios do SUS: prosseguir com a expansão do acesso; consolidar a municipalização, e coordenar a integralidade da assistência. E, fundamentalmente, propor mudanças no modelo mercantilizado e hospitalocêntrico hegemônico no país ${ }^{7,10}$.

Coexistem, na realidade nacional, modelos assistenciais como as Unidades Básicas sem Saúde da Família, organizadas a partir dos princípios das Ações Programáticas em Saúde e suas noções de danos e risco, conforme as conceituações da História Natural das Doenças e da Epidemiologia ${ }^{11-13}$.

O processo de trabalho das Unidades de Atenção Básica prevê: a territorialização; a implementação dos princípios da Programação em Saúde; o acolhimento com escuta qualificada e classificação dos riscos; a avaliação de necessidades/vulnerabilidades; ações educativas, domiciliares e intersetoriais $5^{6,7}$.

\section{Metodologia}

Entre os anos de 2009-2013, desenvolveu-se pesquisa de doutorado com objetivo de investigar os significados de Integralidade de trabalhadores de Unidades Básicas de Saúde de um município do estado de São Paulo. Para coleta de dados, utilizou-se de grupo focal com profissionais lotados em uma Unidade de Atenção Básica sem Saúde da Família (UBS s/SF) e uma Unidade Saúde da Família (USF).

Para evitar constrangimentos aos relatos, considerando-se a posição de coordenação ou o prestígio social de algumas ocupações, optou-se pela divisão em categorias profissionais: a) enfermeiros (as), médicos (as) e dentistas, sendo realizado um encontro com trabalhadores da USF e dois encontros da UBS s/SF; b) auxiliares de enfermagem e de consultório dentário, com dois encontros de cada equipe e, c) agentes comunitários de saúde (ACS), com dois encontros. Assim, foram formados cinco grupos focais, totalizando nove encontros.

As discussões e reflexões pautadas no grupo focal permitiram evidenciar a compreensão das equipes quanto à Integralidade, as condições de trabalho (incluindo vínculos trabalhistas) e a atividade cotidiana realizada.

A análise do material pautou-se no materialismo histórico e dialético, e psicologia histórico-cultural. As principais categorias foram: trabalho/atividade; historicidade; consciência; mediação e totalidade. 
Vecchia e Martins ${ }^{14}$, ao utilizarem esse referencial teórico em pesquisa empírica, destacaram as proposições de Vigotski e Leontiev sobre o caráter social da atividade humana, na qual a "relação com a natureza não se dá somente no sentido de satisfação imediata de necessidades biológicas" (p.184-5). Assim, são próprios do homem: "a organização social do trabalho; a intencionalidade consciente das ações, o uso de meios indiretos (ferramentas e signos), tendo em vista também necessidades subjetivas, [...] descoladas [...] de seu caráter imediato" (p.185).

Apontam para a sociedade de classes, suas diferenças na "apropriação dos instrumentos e dos signos historicamente acumulados, em conformidade com o lugar que o indivíduo ocupa no processo geral de produção /apropriação do trabalho social"14(p.186). Processo que se reflete psiquicamente nas contradições da consciência ${ }^{15}$.

A atividade é categoria central, ponto de partida para novas relações sociais e para intersubjetividade. Implica o compartilhamento de experiências, na formação subjetiva, com transformação de significados e sentidos das práticas sociais. A linguagem assume papel de comunicação e apropriação da realidade, por meio do significado das palavras.

A palavra significada é unidade de análise: encerra as propriedades do pensamento, é mediadora. A palavra (signos) constitui-se em instrumentos psicológicos com fins de comunicação (atividade externa, intersubjetiva) e representação do objeto na consciência (atividade interna, intrasubjetiva) ${ }^{16}$.

Para Vigotski ${ }^{16}$, a palavra expressa na linguagem é mediadora da subjetividade e produto da prática social humana. O significado compõe-se da interface entre pensamento e linguagem, tendo em vista que a palavra sem significado seria som vazio:

Por isso o significado pode ser visto igualmente como fenômeno da linguagem por sua natureza e como fenômeno do campo do pensamento. Não podemos falar do significado da palavra tomado separadamente. O que ele significa? Linguagem ou pensamento? Ele é ao mesmo tempo linguagem e pensamento porque é uma unidade do pensamento verbalizado. Sendo assim, fica evidente que o método de investigação do problema não pode ser outro senão o método de análise semântica, da análise do sentido da linguagem, do significado da palavra. ${ }^{16}$ (p. 10)

Os significados encerram relações que a palavra contém, suas generalizações e conceitos. A atividade humana é sempre significada, representando unidade contraditória do simbólico e emocional: afetos/ emoções são inerentes aos comportamentos e pensamentos ${ }^{16,17}$.

A consciência é formada por significações e sentidos, além de conteúdo sensível (percepção, sensações, córtex cerebral); seu processo especificamente humano constitui-se por meio da (e na) Atividade ${ }^{15,18}$.

A significação é "a forma sob a qual um homem assimila a experiência humana generalizada e refletida"15 (p. 96). Ela é fixada na linguagem "sob a forma de conceitos, de um saber ou saber-fazer" (p. 96), é a generalização da realidade a partir da assimilação da experiência das gerações precedentes.

É fundamental o fato de que o homem se aproprie (ou não) de uma dada significação e em que grau a assimile, o que depende do sentido subjetivo que tal significação tenha para ele. O sentido, como afirma Leontiev, é uma relação que se cria na vida, na atividade do sujeito, e traduz a relação com os fenômenos objetivos conscientizados.

Ao se tomar o significado da palavra como unidade de análise, é possível compreender como cada indivíduo expressa e codifica suas vivências. A fala é a expressão mais imediata da experiência; cabe ao pesquisador ultrapassar a aparência do discurso para buscar as determinações histórico-sociais.

Um método de análise coerente com uma psicologia concreta parte da crítica às visões reducionistas, objetivistas (empiristas) ou subjetivistas, a partir da historicidade, processo e mediação. O empírico é ponto de partida para se buscar a explicação do processo de constituição do objeto estudado ${ }^{19}$.

Analisar um fenômeno significa compreender seu processo histórico, conhecer sua gênese e relações dinâmico-causais, suas contradições, sem perder de vista as relações com a totalidade ${ }^{16}$. 
A análise dos relatos e discussões obtidas nos grupos focais desenvolveu-se a partir da organização dos temas mais frequentes relativos aos objetivos da pesquisa, sendo construídos, com eles, os pré-indicadores temáticos, precursores dos núcleos de significação.

Os pré-indicadores, de acordo com Aguiar e Ozella ${ }^{17,20}$, são caracterizados pela maior frequência (repetição ou reiteração), importância na fala, carga emocional, ambivalências e/ou insinuações.

Após essa etapa, buscou-se a identificação de indicadores (aglutinação dos pré-indicadores), seja pela similaridade, complementaridade e/ou contraposição. Os conteúdos referem-se às fases em que se inserem os dados destacados pelos participantes, assim como remetem-se à particularidade de cada período histórico.

O procedimento da análise sintetiza-se na construção de núcleos de significação, a partir dos indicadores. Com relação ao conceito de integralidade em saúde, os resultados apresentaram três núcleos: 1) Comunicação e interdependência entre os níveis de atenção; 2) Olhar ampliado e sofrimento do trabalhador; 3) Vínculo, acolhimento e cuidado: contradições do processo de trabalho.

Este artigo visa apresentar o primeiro núcleo de significação citado, dada sua maior frequência e homogeneidade na análise da pesquisa.

\section{Resultados}

Ao questionamento: "O que pensam sobre a Integralidade como princípio do SUS?", identificamos que o significado mais frequente referiu-se à Integralidade do Sistema.

De forma desvinculada do modelo tecnológico de APS, este significado mostrou-se presente em todas as discussões grupais. A significação consolidada revela-se relacionada à dimensão da RAS, destacando-se as inter-relações entre os níveis de complexidade do SUS.

Em quatro dos cincos grupos focais, as dificuldades de integração das ações da Unidade Básica com os demais níveis de cuidado foram destacadas com grande conotação afetiva, majoritariamente negativa: motivadora de revoltas/indignação; desânimo/descrédito; impotência frente às limitações na resolubilidade das demandas.

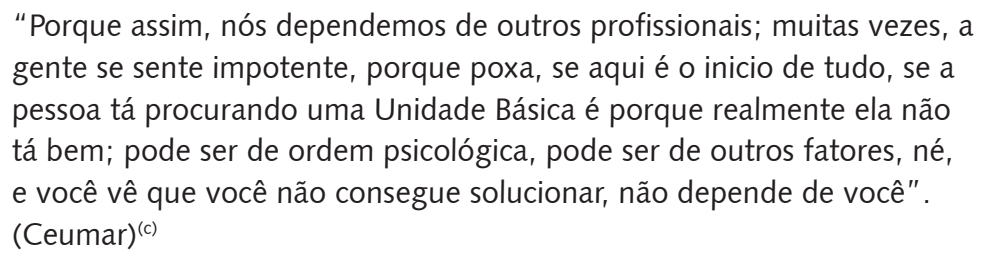

“Daí ele vem atrás da gente: dá a impressão que é a gente que não consegue. Só que não é isso. Então, aqui é complicado mesmo. Aqui... Se você não tiver jogo de cintura, como se diz, a gente enlouquece". (Gal Costa)

(UBS s/Saúde da Família - Auxiliares de Enfermagem) 
“Eu acho que assim, a nossa Unidade Primária seria mais resolvida e a população entenderia mais, se tivesse um seguimento correto. Porque a secundária, terciária, a gente depende deles. $\mathrm{Ai}$, encaminhamento, exames, essas coisas, fica tudo empacado: porque demora. Ai o paciente retorna na Unidade reclamando. E acaba culpando o posto. Agendamento, essas coisas vem tudo com data de lá, não é a gente que resolve essas datas. E daí, na maioria das vezes, eles não compreendem porque que tá demorando. Acham que é a gente que não encaminhou". (Zélia Duncan)

"E ai que é a dificuldade porque aqui é o primeiro contato, mas aqui também é a resposta. Então, fica difícil, né. Você não tem a resposta pra dar; ai a pessoa fica insatisfeita, briga aqui e quem vai escutar é a pessoa que fica aqui". (Elba Ramalho)

(Unidade Saúde da Família - Auxiliares de Enfermagem)

De maneira independente do modelo tecnológico, os trabalhadores revelam que se constituir no centro de comunicação entre os pontos da RAS é uma função distante da prática cotidiana. A incompreensão acerca da importância da Atenção Básica e de suas especificidades demonstradas pelos demais níveis encontra-se como determinante deste distanciamento.

A pouca valorização dos cuidados primários no interior do processo de produção em saúde compõe mediação central para a análise deste fato destacado pelos trabalhadores. A base desse núcleo de significação é formada, assim, a partir das condições concretas do processo de trabalho desenvolvido.

Distantes de se constituir, na prática, em ordenadora do cuidado, a APS transforma-se em executora de políticas seletivas, dando conta de resoluções pautadas em problemáticas aparentemente simples e iniciais.

Foram evidenciados entraves expressos: na falta de vagas em especialidades no âmbito secundário e terciário, nas burocracias dos encaminhamentos, ausência de seguimento, nas consultas eventuais, no descrédito da população para com a Atenção Primária.

Conforme pesquisa de Sala et al. ${ }^{21}$, a ênfase na hierarquização entre os serviços implica avaliações positivas para "o acesso ao especialista", embora a APS não seja "reconhecida como um importante lócus para a resolução de problemas de saúde" (p. 959).

A Rede de Atenção da municipalidade apresenta falhas estruturais que, por vezes, são tomadas, pela população e pelos próprios trabalhadores, como responsabilidades individuais.

Pressionados pelos usuários que não encontram respostas, pelas cobranças dos gestores, e pela frustração pessoal por não desenvolverem o trabalho idealizado, os participantes significam a Integralidade pelas lacunas existentes na relação esgarçada entre a Atenção Primária e os demais níveis da RAS.

“Então, quer dizer, eu vou aqui no secundário e chego lá, o médico me atende e: uma cartinha pro posto de saúde. Primário. Ai volta aqui. Ai aqui, ele dá uma cartinha pedindo encaminhamento pra ir lá pro terciário. Olha só a burocracia". (Djavan)

"Pra vocês verem como é falta de comunicação; não teria de ter uma comunicação entre os três? O primário, secundário e o terciário? Ai fica essa guerra, né. Fica essa guerra: você manda pra lá, outro manda pra cá, e você volta pra lá... Tem paciente que foi pro pronto socorro, voltou aqui, foi pra Unesp e voltou pro pronto-socorro, voltou pra cá; ficou uma semana no vai e vem. [...] Isso daí é um descaso, né. Descaso com a gente que é profissional e mais com o paciente". (Cazuza)

"Se você chega lá, por exemplo, eles não falam assim: "tá faltando o sexo, vamos colocar!" Não! É assim: "é o pessoal do posto que não colocou!". Ai o paciente vem aqui e oh: vem reto em você!". (Gal Costa) 
"Os pacientes vêm aqui: “a Unesp mandou!" Apontam o dedo na sua cara". (Djavan)

(UBS s/Saúde da Família - Auxiliares de Enfermagem)

“Não tem um lugar que a gente possa falar: não, aqui realmente a integralidade funciona. Porque muitas das nossas ações, a gente teria que dar continuidade porque depende dos outros serviços e acaba esbarrando na grande demanda, na falta de acesso. Isso acaba dificultado o seguimento do tratamento do paciente. Muitas vezes, a gente sabe que o paciente precisa daquilo e a gente não tem o que fazer, e ai a gente fica até um pouco frustrado, porque, como é a gente que tem esse vinculo com o paciente, é da gente que ele vai cobrar. [...] Então, você sabe que o paciente vai ficar com aquele problema e a gente não tem o que fazer". (Nara Leão)

(Unidade Saúde da Família - Médicas, enfermeiras e dentista)

A organização do trabalho centrada na figura do médico foi outro ponto destacado pelos participantes; resultado que se mostrou independente do modelo tecnológico e assistencial em que exercem suas funções.

As relações hierárquicas e de poder existentes e as dificuldades relativas ao exercício de uma organização do trabalho integrada foram sinalizadas como impedimentos à resolubilidade.

Resultados semelhantes estão em pesquisa de Vecchia ${ }^{7}$ sobre o trabalho em equipe na Atenção Primária, destacando-se a ausência de condições objetivas para o desenvolvimento do planejamento de ações a partir de reflexões coletivas.

Para tanto, seria necessário dispor-se de tempo, com compreensão adequada da imprescindibilidade dessa atividade para se perseguir a Integralidade da atenção. Identifica-se, desta maneira, que a centralidade do processo de trabalho desenvolvido pela equipe raramente é questionada e refletida à luz das finalidades de atuação?

A totalidade do trabalho de assistência na busca pela autonomia dos usuários tende a diluirse, restringindo-se a consciência às ações técnicas praticadas individualizadamente; portanto, com limitação para significações e sentidos pessoais atribuídos ao papel de cada trabalhador na composição das equipes multiprofissionais.

Na mesma medida em que os elementos citados demonstram, pela negação, os entraves à Integralidade, as especificidades da Atenção Primária, no tocante às possibilidades de um acompanhamento longitudinal ao usuário, com conhecimento do seu "andar" por toda a rede, foram enfatizadas como diferencial das Unidades.

Na comparação com os demais níveis de atenção, as vantagens da assistência na Atenção Primária foram atribuídas à possibilidade de abarcar a totalidade das condições de vida do usuário.

“Eu trabalhava, na época, num hospital privado. Ai apareceu essa oportunidade na prefeitura. Prestei uma vez, não quis entrar: medo do desconhecido, sabe. Até que resolvi prestar de novo e entrei. Nunca tinha trabalhado em Unidade Básica, em Centro de Saúde. E no fim gostei, e tô a todo esse tempo atuando".

"A gente começa a ter visão assim da população; quando você está num hospital privado, você não tem essa noção de dificuldade que a população tem; de como é usado o dinheiro público; de prioridade. Quando você tá fora desse contexto, você não tem essa noção. É diferente quando você está no hospital, né. A necessidade de prevenção... tudo isso você vê quando você está na Unidade de Saúde". (Marisa Monte)

(UBS s/Saúde da Família - Médica, Dentista e Enfermeiras)

Esses resultados encontram ressonância na pesquisa realizada com usuários da APS na capital paulista, evidenciando avaliação positiva nos quesitos relativos à porta de entrada, elenco de serviços 
e coordenação; no entanto, independentemente do modelo tecnológico, "as questões que compõem o enfoque familiar, a orientação comunitária e a acessibilidade receberam as piores avaliações" ${ }^{21}$ (p. 957).

“Ser mais junto, na verdade, né. Porque parece que a gente é uma coisa e eles, outra. Na verdade, a gente é... mas tem que ir formando um elo ali, entre o primário, o secundário e o terciário. E não é assim: cada um faz o seu! E quando alguma coisa dá errado, sempre a culpa é do primário!". (Paula Lima)

(Unidade Saúde da Família - Agentes Comunitários de Saúde)

"Porque a gente tem a nossa resolutividade até um certo ponto; chega uma hora que não dá, tem que encaminhar; e na hora dessa encaminhar é um problema sério". (Marisa Monte)

"Pensando no SUS, né, como modelo: o atendimento integral em todas as áreas, primário, secundário e terciário, a gente não consegue". (Teresa Cristina)

"E pior de tudo, eu acho, é que a gente não tem a resposta depois, né". (Clara Nunes)

"É! Se ele vai, não tem esse feedback. Não tem essa referência e contrarreferência". (Marisa Monte)

(UBS s/Saúde da Família - Médica, Enfermeiras e Dentista)

Dentre as análises relativas aos determinantes da diferença de valoração entre os âmbitos do SUS, Silva Jr. e Alves ${ }^{22}$ chamam a atenção para a organização piramidal dos serviços, cuja lógica advém do paradigma ainda vigente nas relações entre os equipamentos de cuidado, contrariamente à "lógica e relações horizontais, com gestão compartilhada e articulada"6:

De acordo com essa concepção [de sistema piramidal], os serviços terciários são mais valorizados, considerados mais complexos e resolutivos, já que concentram equipamentos e procedimentos e atendem às situações com maior risco de vida. Nesse âmbito, têm grande valor os conhecimentos técnicos necessários, sobretudo ao enfrentamento dos aspectos biológicos da doença e dos agravos à saúde, que são valorizados como verdadeiramente científicos. Como, em geral, não há risco de morte e são poucos os equipamentos utilizados, os serviços básicos são entendidos como simplificados, portanto desvalorizados. ${ }^{22}$ (p.36)

A referida lógica piramidal encontra-se interdependente do projeto neoliberal, com seus mecanismos e novas expressões, evidenciando a "reciclagem do modelo assistencial médico privatista", conforme nos situa historicamente Mendes ${ }^{23}$ (p. 95).

Sob a vigência do modelo neoliberal de Estado, as políticas sociais e de saúde são pautadas por uma universalização excludente, com consequente perpetuação do circuito "má qualidade _expulsão de setores organizados _ baixa atividade reivindicatória _ má qualidade"; calcadas nos subsistemas de cuidado de formato piramidal e segmentação de classe $^{23}$ (p. 98).

De lócus privilegiado para o exercício da Integralidade, a APS se vê pressionada a cumprir metas definidas pelos indicadores de saúde e números de atendimentos, como se pudesse, de maneira isolada, ordenar e regular a integração entre os três níveis de atenção do SUS.

A comunicação inadequada, ausência de contrarreferências, desconhecimento dos trabalhadores dos outros serviços da rede para com a realidade da Atenção Primária compõem elementos concretos da significação relativa à Integralidade do Sistema. 
“É. Porque que nem: manda o paciente ou o particular, ou a Unesp, eles não sabem da realidade do que a gente tem e do que a gente não tem aqui". (Cazuza)

"E falam pro paciente que tem!". (Tulipa Ruiz)

“É. E o paciente vem com aquela ilusão de que aqui tem: 'Não, mas lá falou que tem'. E vem com aquela receita... A gente fala: 'mas a gente não trabalha nem com esse laboratório, não vem pra nós!'"

“'Não, mas a Unesp falou que tem aqui', sabe. Dá dó deles [usuários], porque eles ficam naquela sinuca...". (Cazuza)

(UBS s/Saúde da Família - Auxiliares de Enfermagem)

As análises corroboram pesquisa sobre os sistemas integrados de cuidado e a Atenção Primária. O estudo de Giovanella, Escorel e Mendonça ${ }^{24}$, financiado pelo governo federal a partir do Proesf (Programa de Expansão e Consolidação da Estratégia Saúde da Família), e realizado em dez grandes centros urbanos, apresenta o que se segue sobre a comunicação entre os equipamentos da RAS:

[...] um grande desafio do PSF [Programa Saúde da Família] e da atenção básica em geral é melhorar a comunicação entre profissionais da atenção básica e especialistas e com os serviços de pronto-atendimento e emergência. Os profissionais destes serviços têm formação, concepções e experiências distintas e estabelecer melhor comunicação exige também a ampliação da confiança dos profissionais da atenção secundária nos profissionais de atenção básica para que o especialista promova o retorno do paciente ao serviço de atenção básica. A troca de informações entre os profissionais é essencial para que se possa exercer uma função de coordenador dos cuidados ao paciente. ${ }^{24}$ (p. 286)

As relações entre os conhecimentos produzidos na Atenção Primária e aqueles necessários aos demais níveis de cuidado apresentam mediações complexas que perpassam a própria constituição da medicina enquanto ciência e a sua relação com as práticas sociais.

Mendes-Gonçalves ${ }^{25}$ aponta para historicidade da área enquanto campo científico, no qual a prática médica acaba por distanciar-se das demais práticas sociais, sendo compreendida socialmente como desvinculada de suas relações com o trabalho em si.

Enquanto trabalho, a prática médica, ou quaisquer intervenções em saúde, são determinadas pelos momentos essenciais da atividade: o agente, a finalidade, o objeto ao qual se aplica e os meios para sua realização (os instrumentos). Estes últimos exprimem não apenas soluções técnicas da relação homem-natureza, mas específicas relações sociais, além de determinarem o modo de se procederem as ações do trabalho ${ }^{25}$.

É exatamente a crença na eficácia absoluta da técnica (em seu poder ilimitado) a base mais sólida para a sustentação da medicina, stricto sensu, e sua contribuição político-ideológica à reprodução das relações capitalistas: autonomiza-se a técnica na mesma medida em que se destitui o corpo de sua humanidade. Em outras palavras, "processo de desumanização da doença do doente" 25 (p. 32), como se existisse independente das condições de vida, do modo de andar a vida.

A absolutização e autonomização da técnica que permeia o trabalho médico, desenvolvida historicamente no lócus específico do hospital, com seu conjunto de tecnologias duras ${ }^{26,27}$, aliadas à cientificidade mítica da função médica e ao fetichismo do produto/mercadoria de sua atividade, contribuem para os distanciamentos e valorações diferenciados entre o trabalho dos âmbitos terciários e aqueles desenvolvidos na Atenção Básica. 
Cuidados primários exigem inter-relação com variados campos de conhecimento, científicos ou não. A interdisciplinariedade imprescindível a uma atuação resolutiva, somada à ampliação da concepção sobre o processo saúde-doença, determinam contraposições às especificidades clínicas-hospitalares que, por vezes, impossibilitam diálogos e relações horizontais na produção em saúde ${ }^{7,25}$.

No espaço da Atenção Primária, a técnica não se mostra resolutiva isoladamente; não prescinde das relações intersetoriais, dos diálogos com o movimento da vida, com as diferentes formas de trabalho humano e sua produção de conhecimento, de saúde e de adoecimento; não é eficaz senão nas mediações interdependentes de sua função (e do produto de sua ação) com os demais trabalhos necessários às práticas sociais e, consequentemente, com seus produtos ${ }^{7,25}$.

\section{Considerações finais}

A significação de Integralidade do Sistema revela contradições presentes na Política Nacional de Saúde: definição de Atenção Primária, pautada na ESF, ordenadora da RAS, ampliando o acesso com políticas seletivas, de um lado, e, conforme Marques e Mendes ${ }^{28}$ e Connil${ }^{29}$, descapitalizando os níveis secundário e terciário em nome da transferência ao mercado privado.

Tal contradição não é inédita. Fausto e Matta ${ }^{30}$ apresentam análises referenciadas aos embates econômicos, políticos e ideológicos existentes nas concepções de Atenção Primária seletiva ou integral, desde a Conferência de Alma Ata.

Críticas à adoção de uma seletividade das ações do nível primário conforme as prerrogativas difundidas e financiadas por organismos internacionais (Banco Mundial, OMS) remetem-se à nãointegração de seus serviços aos demais níveis de atenção.

A focalização das políticas sociais aponta para a ineficácia dos resultados de uma Atenção Primária seletiva, já que não resultaram na redução da pobreza e no melhor acesso aos serviços públicos.

O desenvolvimento tecnológico no campo da saúde, o perfil demográfico da população, o surgimento de novas doenças, o retorno de velhos agravos, entre outras questões econômicas e socioepidemiológicas, que dão contornos ao quadro das condições de saúde de uma população, levam a crer que uma visão restrita de atenção primária não corresponde à realidade atual da atenção à saúde.

Atualmente, o quadro epidemiológico geral das populações é marcado pelas doenças crônicas, que cada vez mais compõem o conjunto de ações abordadas na esfera da atenção primária, pressupondo um cuidado integrado a outros níveis de atenção.

Finalmente, o conceito ampliado de saúde, baseado na noção de direito de cidadania, amplitude e diversidade de recursos existentes para lidar com os problemas de saúde de nosso tempo, não comporta ações restritas na APS. ${ }^{30}$ (p. 52)

Os resultados da pesquisa revelam quanto a Atenção Primária segue enfatizando um trabalho médico-centrado, pautado no modelo anatômico-patológico e no consumo de procedimentos.

Contraditoriamente, essa realidade traz consigo as mediações dos acúmulos históricos conquistados nas ciências médicas/biológicas para a cura de variadas doenças, assim como o restabelecimento da saúde e a melhoria da condição de vida.

O avanço científico não é isento de interesses, como a ênfase no modelo médico e hospitalocêntrico demonstram ${ }^{25}$. As necessidades em saúde situam-se em dimensões mais amplas do que aquelas restritas à biologia ou fisiologia humana como o conceito de Integralidade estabelece.

Os significados atribuídos com maior frequência à Integralidade do Sistema mostraram-se de apropriação difundida entre os trabalhadores: quando se pensa o SUS, as relações entre serviços primários, secundários e terciários são facilmente assimiladas, sendo ampla a concepção de interdependência entre âmbitos de complexidades tecnológicas diversas.

Esse núcleo de significados apresenta-se com construção estabilizada desde as proposições iniciais do sistema nacional de saúde, conforme as lutas do movimento sanitário, até as primeiras instituições 
do SUS nos anos 1990. Anteriormente, encontra-se definido no acúmulo da literatura e prática em saúde pública na esfera internacional; com o relatório Dawson, na Inglaterra de 1920, os sistemas integrados de saúde ${ }^{5}$ e a Conferência de Alma-Ata.

O sistema de significações instituído na prática dos cuidados à saúde ao longo da história da humanidade é apropriado e significado pelos trabalhadores na concepção de maior frequência com que expressam a Integralidade.

Desde a RSB, compreendida como articuladora de ações assistenciais e preventivas em quaisquer dos âmbitos de prestação de cuidado ${ }^{3,4}$, encontra-se limitada pelos entraves ao processo de trabalho determinados pela lógica das políticas sociais sob a vigência de práticas contrarreformistas de Estado.

De maneira paradoxal, nas ações cotidianas, uma das dimensões importantes da Integralidade constitui a capacidade dos profissionais de responderem ao sofrimento/adoecimento demandado pelos usuários, assim como, de modo inter-relacional, identificarem e ofertarem, a cada situação singular, ações ou procedimentos preventivos ${ }^{3}$.

Essa concepção é buscada pelas equipes pesquisadas, independente do modelo de atuação. Os relatos reproduzidos neste artigo, além de outros, evidenciam a identificação, solidariedade e compromisso com o trabalho e a população atendida.

\section{Colaboradores}

Lilian Magda de Macedo foi a responsável pela pesquisa de campo, análise do material coletado, revisão e redação do artigo. Sueli Terezinha Ferrero Martin colaborou na análise e discussão dos dados, revisão e redação do artigo.

\section{Referências}

1. Schraiber LB, Nemes MIB, Mendes-Gonçalves RB, organizadores. Saúde do adulto: programas e ações na Unidade Básica. São Paulo: Hucitec; 2000.

2. Cecílio LCO. As necessidades de saúde como conceito estruturante na luta pela integralidade e equidade na atenção em saúde. In: Pinheiro R, Mattos RA, organizadores. Os sentidos da integralidade na atenção e no cuidado à saúde. Rio de Janeiro: UERJ, IMS, Abrasco; 2001. p. 113-26.

3. Mattos RA. Integralidade na prática (ou sobre a prática da Integralidade). Cad Saude Publica. 2004; 20(5):1411-6.

4. Mattos RA. Os sentidos da integralidade: algumas reflexões acerca de valores que merecem ser definidos. In: Mattos RA, Pinheiro R, organizadores. Os sentidos da integralidade na atenção e no cuidado à saúde. 4a ed. Rio de Janeiro: Abrasco/UERJ/ Cepesc; 2006. p. 39-63.

5. Starfield B. Atenção primária: equilíbrio entre necessidades de saúde, serviços e tecnologia. $2^{\mathrm{a}}$ ed. Brasília: Unesco, Ministério da Saúde; 2004.

6. Portaria n 2488, de 21 de outubro de 2011. Aprova a Política Nacional de Atenção Básica, estabelecendo a revisão de diretrizes e normas para a organização da Atenção Básica, para a Estratégia Saúde da Família (ESF) e o Programa Agentes Comunitários de Saúde (PACS). Brasília (DF): Ministério da Saúde; 2011. 
7. Vecchia MD. Trabalho em equipe na atenção primária à saúde: o processo grupal como unidade de análise da dialética cooperação-trabalho coletivo [tese]. Botucatu (SP): Faculdade de Medicina de Botucatu; 2011.

8. Baptista TWF, Fausto MCR, Cunha MS. Análise da produção bibliográfica sobre atenção primária à saúde no Brasil em quatro periódicos selecionados. Physis. 2009; 19(4):1007-28.

9. Teixeira CF. A mudança do modelo de atenção à saúde no SUS: desatando nós, criando laços. Saude Debate. 2003; 27(65):257-77.

10. Portaria $n^{\circ} 1889$, de 18 de novembro de 1997. Aprova Normas e Diretrizes do Programa Agentes Comunitários da Saúde e do Programa Saúde da Família. Legislação do SUS. Brasília (DF): CONASS; 2003.

11. Paim JS. As bases conceituais da reforma sanitária. In: Fleury $S$, organizadora. Saúde e democracia: a luta do CEBES. São Paulo: Lemos; 1997. p. 11-24.

12. Nemes MIB. Ação programática em saúde: recuperação histórica de uma política de recuperação. In: Schraiber LB, organizadora. Programação em saúde hoje. São Paulo: Hucitec; 1990. p. 65-117.

13. Schraiber LB, organizadora. Programação em saúde hoje. São Paulo: Hucitec; 1990.

14. Vecchia MD, Martins STF. Concepções dos cuidados em saúde mental por uma equipe de saúde da família, em perspectiva histórico-cultural. Cienc Saude Colet. 2009; 14(1):183-93.

15. Leontiev AN. O desenvolvimento do psiquismo. Lisboa: Horizonte Universitário; 1978.

16. Vigotski LS. A construção do pensamento e da linguagem. São Paulo: Martins Fontes; 2001.

17. Aguiar WMJ, Ozella S. Núcleos de significação como instrumento para apreensão da constituição dos sentidos. Psicol Cienc Prof. 2006; 26(2):222-45.

18. Vigotski LS. Análisis de las funciones psíquicas superiores. In: Vigotski LS, organizador. Historia del desarrollo de las funciones psíquicas superiores. Kuper $L$, tradutora. Madrid: Visor; 1995. p. 97-120. (Obras escogidas, III)

19. Vigotski LS. O significado histórico da crise da Psicologia: uma investigação metodológica. In: Vigotski LS, organizador. Teoria e método em Psicologia. Berliner C, tradutora. 3a ed. São Paulo: Martins Fontes; 2004. p. 203-417.

20. Aguiar WMJ, Ozella S. Apreensão dos sentidos: aprimorando a proposta dos núcleos de significação. Rev Bras Estud Pedag. 2013; 94(236):299-322.

21. Sala A, Luppi CG, Simões $O$, Marsiglia R. Integralidade e Atenção Primária à Saúde: avaliação na perspectiva dos usuários de unidades de saúde do município de São Paulo. Saude Soc. 2011; 20(4):948-60.

22. Silva Júnior AG, Alves CA. Modelos assistenciais em saúde: desafios e perspectivas. In: Morosini MVGC, organizador. Modelos de atenção e a Saúde da Família. Rio de Janeiro: EPSJV/Fiocruz; 2007. p. 27-41.

23. Mendes EV. Distrito sanitário: o processo social de mudança das práticas do Sistema Único de Saúde. São Paulo: Hucitec; 1995.

24. Giovanella L, Escorel S, Mendonça MHM. Porta de entrada pela atenção básica? Integração do PSF à rede de serviços de saúde. Saude Debate. 2003; 27(65):278-89.

25. Mendes-Gonçalves RB. Medicina e história: raízes sociais do trabalho médico [dissertação]. São Paulo (SP): Faculdade de Medicina, Universidade de São Paulo; 1979. 
26. Merhy EE, Chakkour M, Stéfano ME, Santos CM, Rodrigues RA, Oliveira PCP. Em busca de ferramentas analisadoras das tecnologias em saúde: a informação e o dia a dia de um serviço, interrogando e gerindo trabalho em saúde. In: Merhy EE, Onocko $\mathrm{R}$, organizadores. Agir em saúde: um desafio para o público. 3a ed. São Paulo: Hucitec; 2007. p. 113-50.

27. Merhy EE. Em busca do tempo perdido: a micropolítica do trabalho vivo em saúde. In: Merhy EE, Onocko R, organizadores. Agir em saúde: um desafio para o público. $3^{\mathrm{a}}$ ed. São Paulo: Hucitec; 2007. p. 71-112.

28. Marques RM, Mendes A. A política de incentivos do Ministério da Saúde para a atenção básica: uma ameaça à autonomia dos gestores municipais e ao princípio da integralidade? Cad Saude Publica. 2002; 18 Supl.:163-71.

29. Conill EM. Ensaio histórico-conceitual sobre a Atenção Primária à Saúde: desafios para a organização de serviços básicos e da Estratégia Saúde da Família em centros urbanos no Brasil. Cad Saude Publica. 2008; 24 Supl. 1:7-16.

30. Fausto MCR, Matta GCA. Atenção primária à saúde: histórico e perspectivas. In: Morosini MVGC, organizador. Modelos de atenção e a Saúde da Família. Rio de Janeiro: EPSJV/Fiocruz; 2007. p. 43-67.

Macedo LM, Martin STF. Interdependencia entre los niveles de atención del Sistema de Salud Brasileño (SUS): significado de integralidad presentado por trabajadores de la Atención Primaria. Interface (Botucatu). 2014; 18(51):647-59.

La integralidad constituye un importante principio del SUS, conquistado con las luchas del movimiento sanitario brasileño. Representa la ampliación de los conceptos de salud y enfermedad, abarcando los factores determinantes sociales de las necesidades en salud. Una investigación de los significados de la integralidad presentados por trabajadores de Atención primaria se desarrolló en un municipio de mediano porte del estado de São Paulo, envolviendo distintos modelos tecnológicos de organización del trabajo en las Unidades Básicas de Salud. La dimensión de integralidad del sistema surgió con mayor frecuencia, conforme análisis a partir de grupos focales. Los trabajadores señalaron las dificultades de integración y comunicación entre los niveles de atención a la salud, determinadas por políticas sociales selectivas y servicios de mediana/alta tecnología delegados al mercado privado. Las contribuciones teórico-filosóficas del estudio se basaron en la Psicología Histórico-Cultural, a partir de las categorías: trabajo/actividad; conciencia; mediación y totalidad.

Palabras clave: Integralidad. Atención primaria en salud. Psicología histórico-cultural. Políticas sociales. Trabajo. 
